\title{
Intergenerational and intrafamilial phenotypic variability in 22q11.2 Deletion syndrome subjects
}

\author{
Emilia Cirillo ${ }^{1}$, Giuliana Giardino ${ }^{1}$, Vera Gallo ${ }^{1}$, Pamela Puliafito ${ }^{2}$, Chiara Azzari ${ }^{3}$, Rosa Bacchetta ${ }^{4}$, Fabio Cardinale ${ }^{5}$, \\ Maria Pia Cicalese ${ }^{6}$, Rita Consolini $^{7}$, Silvana Martino ${ }^{8}$, Baldassarre Martire $^{9}$, Cristina Molinatto $^{8}$, Alessandro Plebani $^{10}$, \\ Gioacchino Scarano ${ }^{11}$, Annarosa Soresina ${ }^{10}$, Caterina Cancrini ${ }^{2}$, Paolo Rossi ${ }^{2}$, Maria Cristina Digilio ${ }^{12 \dagger}$ \\ and Claudio Pignata ${ }^{1,13^{*}+}$
}

\begin{abstract}
Background: 22q11.2 deletion syndrome (22q11.2DS) is a common microdeletion syndrome, which occurs in approximately 1:4000 births. Familial autosomal dominant recurrence of the syndrome is detected in about 8-28\% of the cases. Aim of this study is to evaluate the intergenerational and intrafamilial phenotypic variability in a cohort of familial cases carrying a 22q11.2 deletion.

Methods: Thirty-two 22q11.2DS subjects among 26 families were enrolled.

Results: Second generation subjects showed a significantly higher number of features than their transmitting parents (212 vs 129, $P=0.0015$ ). Congenital heart defect, calcium-phosphorus metabolism abnormalities, developmental and speech delay were more represented in the second generation $(P<0.05)$. Ocular disorders were more frequent in the parent group. No significant difference was observed for the other clinical variables. Intrafamilial phenotypic heterogeneity was identified in the pedigrees. In 23/32 families, a higher number of features were found in individuals from the second generation and a more severe phenotype was observed in almost all of them, indicating the worsening of the phenotype over generations. Both genetic and epigenetic mechanisms may be involved in the phenotypic variability.

Conclusions: Second generation subjects showed a more complex phenotype in comparison to those from the first generation. Both ascertainment bias related to patient selection or to the low rate of reproductive fitness of adults with a more severe phenotype, and several not well defined molecular mechanism, could explain intergenerational and intrafamilial phenotypic variability in this syndrome.
\end{abstract}

Keywords: 22q11.2 deletion syndrome, DiGeorge syndrome, Immunodeficiency, Phenotypic variability

\section{Background}

Chromosome 22q11.2 deletion syndrome (22q11.2DS), also known as DiGeorge or velocardiofacial syndrome (OMIM\#188400), occurs in approximately 1:4000 live births [1,2]. Major clinical features include facial anomalies, conotruncal cardiac defects, palatal anomalies, neonatal hypocalcaemia, mild to moderate immune deficiency related to thymic a/hypoplasia [3-5], developmental and speech delay [6]. Ocular, renal and skeletal anomalies may

\footnotetext{
*Correspondence: pignata@unina.it

${ }^{\dagger}$ Equal contributors

'Department of Translational Medicine, "Federico II" University, Naples, Italy

${ }^{13}$ Department of Translational Medical Sciences, Unit of Pediatric

Immunology, "Federico II" University, via S. Pansini, 5-80131 Naples, Italy

Full list of author information is available at the end of the article
}

also be found. However, the syndrome has a very wide spectrum of phenotypic features $[7,8]$. Evidence highlighted that subjects carrying the deletion may have only mild phenotypes $[9,10]$. Psychiatric or autoimmune disorders [11] can be the features leading to the diagnosis in adolescents and adults, and, in particular, among adults, they may be the unique clinical feature $[12,13]$. The identification of subjects with attenuated phenotypes is leading to the understanding that the syndrome is more frequent than previously thought and to focus on novel atypical presentations. A wide clinical variability has also been reported even within the same family $[9,10,14,15]$ and a phenotypic discordance has been described among monozygotic twins [16,17]. Genetic modifiers, chance association or environmental interactions have been proposed

\section{Biomed Central}


to explain the intrafamilial variability. Somatic mosaicism or post zygotic second hit have also been hypothesized as potential mechanisms underlying such phenotypic discordance, even though, to date, no definitive explanation is available.

The deletion results from non allelic homologous recombination, occurring during meiosis and mediated by low-copy repeats (LCR) on chromosome 22 [18-20]. Most patients have a deletion of the same $3 \mathrm{Mb}$ region on $22 \mathrm{q} 11.2$, including about 30 genes, whereas in $8 \%$ of the cases a smaller deletion of $1.5 \mathrm{Mb}$, which contains 24 genes, is found. So far, no correlation between the severity of the phenotype and the different size of the deletion has been documented [21]. Both deletions include the TBX1 gene, a member of the T-box family genes. Mice, haploinsufficient for TBX1, share several features with humans carrying the homologous deletion, and, in particular, structural cardiac anomalies [22]. Interestingly, both gain or loss of function mutations in TBX1 have been reported in human subjects exhibiting a DiGeorge-like phenotype [23].

In most cases, the deletion is a sporadic event, while in $8-28 \%$ of the cases the syndrome is inherited in an autosomal dominant fashion [8,10,24-26].

Several studies have analyzed the phenotypic variability of the syndrome, but an extensive and conclusive intergenerational and intrafamilial comparison has not yet been reported.

The aim of this study is to perform an intergenerational and intrafamilial comparison of the clinical phenotype in a cohort of patients affected with inherited chromosome 22q11.2DS.

\section{Methods}

\section{Patients}

Thirty-two subjects (18 females) affected with familial 22q11.2DS from 26 families, were enrolled into the study. The study and data collection, approved by the local Ethics Committee for Biomedical activities "Carlo Romano", have been performed upon informed consent and in compliance with the Helsinki Declaration (http://www.wma. net/en/30publications/10policies/b3/index.html). Within the group, 17 subjects were from the Italian Network for Primary Immunodeficiencies (IPINET) Registry, followed at 8 Italian Centers, and 15 were referred to two Genetic Units. In 4 families, 2 affected siblings were diagnosed and in one further family, 3 subjects were identified. Mean age +/- SD was $10.4+/-7.23$ years (range 4 months31 years). The parent carrying the deletion was the mother in 17 cases (65\%) and the father in 9 (35\%). Mean age +/- SD of carrier parents was $39.8+/-7.9$ years (range 21-58 years). We found a preferential maternal transmission, in keeping with the recent observation that female sex represents a significant positive predictor of fitness. All the parents were identified as affected by 22q11.2DS after the birth of a child with the deletion. All patients, but two, were Caucasian. Demographical features are reported in Additional file 1: Table S1. Clinical data of the second generation subjects were obtained, upon informed consent, through the IPINET Registry or from the referring Units. Data on parents carrying the deletion were collected at each Center. Each subject underwent a clinical and laboratory evaluation protocol (IPINET protocol for 22q11.2DS) available at the site http://www.aieop.org. The protocol included cardiologist examination, echocardiography and abdominal ultrasound, which were performed in order to exclude subclinical cardiac or abdominal defects in asymptomatic subjects. To exclude thyroid and calcium-phosphorus abnormalities, the serum levels of calcium, phosphorus, parathyroid hormone, TSH and FT4 were evaluated. History of speech therapy or speech pathologist interventions were recorded for the evaluation of language disorders. The Wechsler Intelligence Scale for Children (WISC) and the Wechsler Adult Intelligence Scale (WAIS) were used for the assessment of cognitive function in subjects of the second generation and in their parents, respectively. Each Center reported the presence/ absence of intellectual disability which was defined as an IQ under 70. Neuropsychiatric evaluation was performed by skilled clinicians using the Schedule For Affective Disorders and Schizophrenia for School-aged Children, Present and Lifetime (K-SADS-PL). The second generation subjects, older than 18 years, and their parents were interviewed with the Structured Clinical Interview for Axis I DSM IV Disorders (SCID).

Among the clinical features, birth defects, facial anomalies, gastrointestinal disorders, infections and autoimmune manifestations were recorded. History of neonatal hypocalcaemia was also considered. In 6 families, data were also obtained from the non-deleted parent, to exclude potential interfering factors not related to the 22q11.2 deletion.

Intrafamilial phenotypic variability was assessed through the evaluation of the clinical phenotype in each parentchild couple. Since in 5 families more than 1 subject with the inherited deletion was detected, the phenotype was analyzed in a total number of 32 parent-child pairs from the 26 families.

\section{Cytogenetic analysis}

The diagnosis of 22q11.2DS was performed by fluorescence in situ hybridization (FISH) analysis and/or multiplex ligation-dependent probe amplification (MLPA) using probes for 22q11 region in all affected patients. In one case, the diagnosis was obtained through a CGH array with whole-genome oligonucleotide microarray Agilent Technologies (Santa Clara, CA) according to the manufacturer protocol. 


\section{Statistical analysis}

Statistical analysis was performed using the Student"s $t$ test or the Fisher exact Test. Values of $P<0.05$ were considered statistically significant. The calculations were performed using InStat software.

\section{Results}

Intergenerational clinical phenotypic comparison

Seventeen clinical variables were evaluated in subjects of the second generation and their parents (Table 1), for a total number of 544 and 442 variables in the first and second group, respectively. Overall, affected subjects of the second generation showed a significantly higher number of features than their parents ( $212 \mathrm{vs} 129, P=0.0015)$. In particular, congenital heart defect (CHD) (62.5 vs $7 \%, P<0.0001)$, developmental delay $(71.8$ vs $42.3 \%$, $P=0.032)$, speech delay (75 vs $46.1 \%, P=0.031)$ and calcium-phosphorus abnormalities (37.5 vs $3.8 \%$, $P=0.0033)$ were more represented in the second generation. Conversely, ocular disorders were more frequent in the parents than in their affected children ( 3.1 vs $23 \%$, $P=0.037)$. Psychiatric (12.5 vs $34.6 \%)$, autoimmune (12.5 vs $19.2 \%$ ) and dental disorders ( 25 vs $38.4 \%$ ) tended to be more frequent in the older generation, even though the differences did not reach a statistical significance. No Table 1 Clinical characteristics of second generation
subjects and parents carrying the $22 q 11.2$ deletion

\begin{tabular}{|c|c|c|c|}
\hline \multirow{3}{*}{ Total number of subjects } & Second generation & Parents & \multirow[b]{3}{*}{$\mathrm{p}$} \\
\hline & 32 & 26 & \\
\hline & N (\%) & N (\%) & \\
\hline Facial anomalies & $29(90.6)$ & $24(92.3)$ & 1 \\
\hline Congenital heart defect & $20(62.5)$ & $2(7)$ & $<0.0001$ \\
\hline Ca-P abnormalities & $12(37.5)$ & $1(3.8)$ & 0.0033 \\
\hline Palatal anomalies & $18(56.2)$ & $13(50)$ & 0.79 \\
\hline ENT anomalies & $4(12.5)$ & $2(7)$ & 0.68 \\
\hline Renal disorders & $7(21.8)$ & $2(7)$ & 0.16 \\
\hline Ocular disorders & $1(3.1)$ & $6(23)$ & 0.037 \\
\hline Neurological disorders & $3(9.3)$ & $1(3.8)$ & 0.62 \\
\hline Dental anomalies & $8(25)$ & $10(38.4)$ & 0.39 \\
\hline Skeletal anomalies & $15(46.8)$ & $10(38.4)$ & 0.6 \\
\hline Gastrointestinal disorders & $8(25)$ & $2(7)$ & 0.16 \\
\hline Psychiatric disorders & $4(12.5)$ & $9(34.6)$ & 0.06 \\
\hline Language delay & $24(75)$ & $12(46.1)$ & 0.031 \\
\hline Developmental delay & $23(71.8)$ & $11(42.3)$ & 0.032 \\
\hline Learning difficulty & $23(71.8)$ & $16(61.5)$ & 0.57 \\
\hline Autoimmunity & $4(12.5)$ & $5(19.2)$ & 0.71 \\
\hline Infections & $9(28.1)$ & $3(11.5)$ & 0.19 \\
\hline
\end{tabular}

Only severe infections (sepsis, pneumoniae), requiring hospitalization, or history of recurrent infections were considered. Bold indicate $P$ values considered statistically significant. statistically significant difference was observed for the other phenotypic features. About $15 \%$ of the clinical features were diagnosed during the study.

We next compared the anatomic type of CHD between the 2 groups. We found that in the $20 \%$ of the subjects of the second generation with CHD, each individual patient had more than 1 abnormality, whereas in the parent group none of them had a more severe defect. A cyanotic CHD was found only in the $35 \%$ of the group with the cardiac defect. In particular, among these patients, we found that $7 / 20$ subjects of the second generation exhibited a tetralogy of Fallot (TOF) and only 1/20 truncus arteriosus (TA). Among those with non cyanotic CHD, a patent ductus arteriosus (PDA) was observed in $4 / 20$, atrial septal defects (ASD) in $4 / 20$, interrupted aortic arch (IAA) in $4 / 20$, ventricular septal defects (VSD) in $3 / 20$, pulmonary valve stenosis (PVS) in $1 / 20$ and other in $2 / 20$. In the parent group, the anomalies found were a PDA in one case and a double aortic arch (DAA) in the other one.

With regard to calcium-phosphorus metabolism abnormalities, 9 subjects in the second generation presented with neonatal hypocalcemia, and in 2 of them a hypoparathyroidism was later diagnosed. Overall, at any age, a total of 5/32 (15.6\%) of them received a full diagnosis of hypoparathyroidism. Only 1 subject of the parent group was affected with asymptomatic hypoparathyroidism.

Although the prevalence of the palatal defects was similar in the 2 groups (56 and 50\%, respectively), we next compared the type of the defect and made a comparison. Within the group of patients of the second generation, 1 subject had cleft palate and bifid uvula, 16 velopharyngeal insufficiency, 4 hypernasal speech and 4 high arched palate. In the parent group, 11 had velopharyngeal insufficiency, 3 hypernasal speech, 1 high arched palate. Only in two parents, a cleft palate was observed. Thus, no remarkable difference was found for these variables.

Psychiatric disorders were more frequent in the parent group, even though the difference did not reach statistical significance $(P=0.06)$. We found that in the parent group, anxiety was observed in $5 / 26$, mood disorders in $3 / 26$, attention-deficit/hyperactivity disorders in $3 / 26$, behavioral anomalies in $3 / 26$, schizophrenia in $2 / 26$, psychotic disorders not otherwise specified (NOS) in $2 / 26$ and phobia in $1 / 26$. Within the second generation group, 2 of them had behavioral abnormalities represented by trend to social isolation and rejection, impairment in social and daily living skills and low self-esteem, 1 also showed adaptive abnormalities, and the other one an attention deficit disorder. Schizophrenia was observed in 1 subject of the second generation, who, however, was 31 years-old.

Ocular defects were the only anomaly frequently observed in the parental generation, consisting in refractive defects (3/6), strabismus (2/6), retinal vessel abnormalities 
$(1 / 6)$, cataract (1/6) and xerophthalmia (1/6). The only child with ocular defect had retinal vessels abnormalities.

\section{Intrafamilial clinical phenotypic comparison}

With regard to the intrafamilial phenotypic variability, in 23 out of the 32 child/parent couples a higher number of features was found in the second generation, although in 6 couples the number of features was higher in the parents' generation and in the remaining 3 couples no difference was found (Figure 1). None of the couples with higher number of features in the parents' generation had a CHD or hypoparathyroidism.

We then performed an intrafamilial evaluation of the clinical severity of the phenotype with regard to the prominent clinical features, whose prevalence was statistically different between the 2 groups, namely CHD, anomalies of the calcium-phosphorus metabolism, developmental and/or speech delay (Table 2).

In particular, we observed that $\mathrm{CHD}$ was present in 18 couples only in the second generation and, in one case, only in the first generation. In the couple in which both members were affected, the parent exhibited a PDA, whereas his child was affected with IAA, thus confirming the lack of phenotypic correspondence. Calciumphosphorus abnormalities were found in 11 subjects of the second generation, and the only parent with asymptomatic hypoparathyroidism had a child who presented with hypocalcaemia. In 15 couples speech delay was exclusively observed in the second generation whereas in 5 couples only in the first generation. In the remaining 9 couples both members were affected. In 16 couples, developmental delay was exclusively found in the second generation, in 4 cases only in the first generation and in 8 couples both subjects were affected.

To rule out the interference of factors not related to the 22q11.2 deletion, in 6 families, data were collected also from the non-deleted parent. Of note, none of them had a CHD, while 2 children in this subgroup were affected. One subject reported learning and behavioral problems, but not intellectual disabilities, while in another case a borderline IQ of 68 was determined.

Furthermore, in the families with more than one affected child, a milder phenotype was observed in parents than in children, even though the 5 subjects of the second generation, who were diagnosed first, had a higher number of the major clinical features compared to their 6 siblings (16 core features vs 11$)$.

\section{Discussion and conclusions}

We have compared the clinical phenotype of a cohort of 32 subjects affected with inherited 22q11.2DS and their transmitting parents.

In this study, we found a higher number of clinical features and a more severe phenotype in the second generation, which exhibited a higher number of more severe conditions. CHD, abnormalities of the calciumphosphorus metabolism, developmental and/or speech delay were more represented in children than in parents. It should be considered that, in the past decades, severe CHD was associated with a high neonatal and infant mortality. This evidence was thought to have an appreciable impact on reducing the reproductive fitness of 22q11.2DS patients with CHD. More recently, however, with the improvement of cardiac surgery strategies, it is suggested

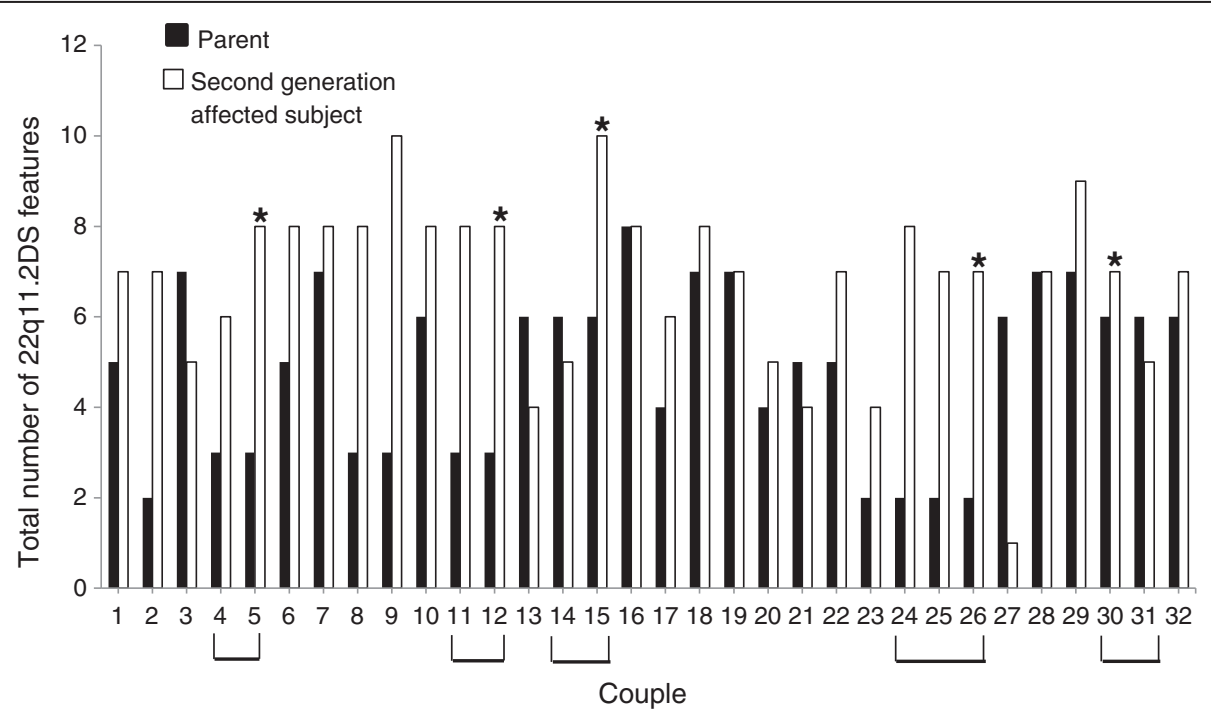

Figure 1 Intrafamilial phenotypic comparison. A higher number of features were observed in the second generation in 23 couples. In 6 couples the number of features was higher in the parents' generation and in the remaining 3 couples no difference was found. The brackets indicate the families with 2 or more second generation affected subjects. * indicates the proband within these families. 
Table 2 Intrafamilial comparison of the clinical severity of the phenotype

\begin{tabular}{|c|c|c|c|c|c|c|c|c|}
\hline \multirow[t]{2}{*}{ Couple } & \multicolumn{2}{|c|}{ Congenital heart defect } & \multicolumn{2}{|c|}{ Ca-P abnormalities } & \multicolumn{2}{|c|}{ Speech delay } & \multicolumn{2}{|c|}{ Developmental delay } \\
\hline & Affected subject & Parent & Affected subject & Parent & Affected subject & Parent & Affected subject & Parent \\
\hline 1 & yes & no & yes & yes & no & yes & yes & no \\
\hline 2 & yes & no & yes & no & yes & no & no & no \\
\hline 3 & yes & no & no & no & no & yes & yes & no \\
\hline${ }^{\circ} 4$ & no & no & yes & no & no & yes & yes & no \\
\hline${ }^{\circ} 5^{\delta}$ & yes & no & yes & no & yes & yes & yes & no \\
\hline 6 & yes & no & no & no & yes & yes & yes & yes \\
\hline 7 & yes & no & yes & no & yes & no & yes & no \\
\hline 8 & no & no & no & no & yes & no & yes & no \\
\hline 9 & no & no & no & no & yes & no & yes & no \\
\hline 10 & no & yes & yes & yes & yes & yes & no & no \\
\hline${ }^{\circ} 11$ & yes & no & yes & no & no & no & yes & no \\
\hline${ }^{\circ} 12^{\delta}$ & yes & no & no & no & yes & no & yes & no \\
\hline 13 & no & no & no & no & yes & no & no & yes \\
\hline${ }^{\circ} 14$ & no & no & no & no & yes & no & yes & yes \\
\hline${ }^{\circ} 15^{\delta}$ & yes & no & no & no & yes & no & no & yes \\
\hline 16 & no & no & no & no & yes & no & yes & no \\
\hline 17 & yes & no & no & no & yes & yes & yes & yes \\
\hline 18 & yes & no & no & no & yes & yes & yes & yes \\
\hline 19 & yes & no & no & no & yes & yes & no & yes \\
\hline 20 & yes & yes & no & yes & yes & yes & yes & no \\
\hline 21 & yes & no & yes & no & yes & yes & yes & yes \\
\hline 22 & yes & no & yes & no & yes & yes & yes & yes \\
\hline 23 & yes & no & yes & no & yes & no & yes & yes \\
\hline${ }^{\circ} 24$ & no & no & no & no & yes & no & yes & no \\
\hline${ }^{\circ} 25$ & no & no & no & no & yes & no & yes & no \\
\hline${ }^{\circ} 26^{\delta}$ & yes & no & yes & no & yes & no & yes & no \\
\hline 27 & yes & no & yes & no & no & yes & no & yes \\
\hline 28 & no & no & no & no & yes & yes & yes & yes \\
\hline 29 & no & no & no & no & yes & no & yes & no \\
\hline${ }^{\circ} 30^{\delta}$ & yes & no & no & no & yes & no & yes & no \\
\hline${ }^{\circ} 31$ & no & no & no & no & no & no & no & no \\
\hline 32 & yes & no & no & no & no & no & no & no \\
\hline
\end{tabular}

${ }^{\circ}$ Couple of siblings; ${ }^{\delta}$ First individual to seek medical attention for genetic evaluation.

that a stronger negative selective pressure against the transmission of $22 \mathrm{q} 11.2$ deletion is primarily due to the severity of the neuropsychiatric phenotype and intellectual disabilities [27].

The only anomalies more frequent in the parental generation were ocular abnomalities. Since most of them, in particular refractive defects and cataract usually develop during older age, we could not exclude a bias related to the different ages of the subjects in the two groups.
When an intrafamilial comparison of the phenotypic complexity was performed, a higher prevalence of clinical features were found in the second generation. When the comparison concerned the prominent clinical features, whose prevalence was statistically different between the 2 groups, namely $\mathrm{CHD}$, calcium-phosphorus metabolism anomalies, developmental delay and speech delay, we observed that in almost all parent/child couples these major features were more frequent in the second generation. In previous studies $[9,10,13-15,24]$, an intrafamilial 
variability has already been reported, even though the comparison of intergenerational clinical features has not been performed. An ascertainment bias could partially explain this finding, since the first subject diagnosed within a family is likely to be more severely affected. Moreover, our observation may also be explained by a bias related to the low rate of reproductive fitness of adults with a more severe phenotype.

As to developmental delay, the presence of environmental intellectual disabilities may obviously per se influence the mental development of the offspring, because of psychosocial deprivation. However, it should be emphasized that in our cohort the majority of the subjects with developmental delay have a parent without intellectual disability. Moreover, in the 6 families in which also the non-deleted parent was studied, the lack of a clear correlation between environment and the child' development was noted. As expected, psychiatric disorders were more represented in the first generation, however, the difference was not significant thus suggesting the need of an accurate psychiatric management since childhood.

Several genes, such as TBX1 [28], HIRA, UFD1L [29] and $C R K L$ [30], within the 22q11 region have been considered to be implicated in the pathogenesis of the syndrome. The 22q11.2 phenotype is a developmental field defect, and a DiGeorge-like phenotype may also occur in the absence of the deletion [31], as in diabetic [32] and retinoic acid embryopathy, fetal alcohol syndrome, CHARGE [33] and Fraser syndromes, as well as other chromosomal anomalies, such as 10p13, 17p13, 4q34.1q35.2 [34-36], indicating that several molecules in a common genetic pathway or in functionally related pathways may be involved in 22q11.2DS clinical manifestations.

Several hypotheses have so far been proposed to explain intergenerational and intrafamilial phenotypic variability in genetic syndromes. Deletions of different sizes and location and the extension of an unstable mutation at the 22q11.2 locus could explain the clinical variability [37].

Evidence indicates that TBX1 gene is sensitive to altered dosage [38], thus leading to the hypothesis that additional alterations of the other allele may explain the clinical variability. In humans, this does not seem to be the case, in that so far DNA variations in TBX1 locus on the remaining allele were not found in 22q11.2DS patients exhibiting a variable cardiovascular expression and palatal defects. Thus, it is likely that gene modifiers not related to chromosome 22 may be implicated $[39,40]$.

The increased risk of cardiac defects observed in unaffected relatives of 22q11.2DS subjects with CHD, suggested a potential role for genes outside the DiGeorge critical region $[41,42]$. However, studies aimed at identifying genetic factors outside of the 22q11,2 region, such as VEGFA [43] or folate-related genes [44] failed to reveal any association. It should be noted that in the subgroup of families in whom also the non-deleted parent was studied, no $\mathrm{CHD}$ was noted suggesting the absence of interfering genetic factors not related to the $22 \mathrm{q} 11.2$ deletion in this context.

A copy-number variation may explain a reduced penetrance of some disease-causing mutations [45]. A genetic compensatory effect has also been documented in families of 22q11.2DS subjects, whose clinically normal parent carried 22q11.2 deletion compensated by an insertion of the 22q11.2 critical region inside the other copy of the chromosome [46]. Finally, a mosaic status in the carrier parent, even though rare, could be the explanation of the variable and more benign phenotype. At the moment, we cannot yet exclude the presence of a concomitant duplication or copy number variations in the former generation, since further studies with interphase FISH or array-CGH are required to rule out this hypothesis.

During development, gene expression is accurately orchestrated in time and space in a program that involves enzymes controlling nucleosome remodeling, histone modification and DNA methylation [47]. A demonstration that an epigenetic alteration could result in a DiGeorge syndrome phenocopy has been recently documented in mutant mice lacking the MOZ histone acetyltransferase [48]. Thus, failure of these fine tuned mechanisms could result in an interference of the phenotypic expression.

In our study we also observed that some clinical features were more represented in the previous generation, although the difference did not reach the statistical significance for the limited number of subjects studied. In keeping with recent findings, we observed a higher incidence of psychiatric disorders in the older generation.

The identification of adults with a milder phenotype deserves careful attention since a later onset illness associated with 22q11.2DS has been reported, highlighting the possibility that along with psychiatric disorders, also treatable conditions such as symptomatic or asymptomatic hypocalcaemia, thrombocytopenia and hypothyroidism may occur [49]. Early recognition of these features [50] could provide the benefit of an early treatment [51-53].

\section{Advantages and limitations of the study}

This is the largest cohort of subjects affected with familial 22q11.2DS. A detailed characterization of the clinical features of such subjects, and an intergenerational/intrafamilial clinical comparison has been performed. The observation that within the families, the patients who were first diagnosed had a higher number of core features as compared to their siblings or parents would suggest an ascertainment bias, even though the clinical phenotype of the parents was milder compared to their children. Another possible explanation could be the co-inheritance of a further genetic defect from the non-affected parent. This seems unlikely since this co-inheritance should have 
occurred in all cases exhibiting the worsening of the phenotype. As for the CHD, it should be noted that none of the non-affected parents had a CHD, thus excluding, at least for this feature, this hypothesis.

\section{Additional file}

Additional file 1: Table S1. Demographic characteristics of the 22q11.2DS subjects.

\begin{abstract}
Abbreviations
22q11DS: 22q11.2 Deletion syndrome; LCR: Low-copy repeats; IPINET: Italian network for primary immunodeficiencies; WISC: Wechsler intelligence scale for children; WAIS: Wechsler adult Intelligence Scale; FISH: Fluorescence in situ hybridization; MLPA: Multiplex ligation-dependent probe amplification; CGH: Comparative genoma hybridization; CHD: Congenital heart defect; TOF: Tetralogy of Fallot; TA: Truncus Arteriosus; PDA: Patent Ductus Arteriosus; ASD: Atrial septal defects; IAA: Interrupted Aortic Arch; VSD: Ventricular septal defects; PVS: Pulmonary valve stenosis; DAA: Double aortic arch.
\end{abstract}

\section{Competing interests}

The authors declare that they have no competing interests.

\section{Authors' contributions}

CE conceptualized and designed the study, enrolled patients and collected data, drafted the initial manuscript. GG, VG enrolled patients, collected data and coordinated data collection from each group, drafted the initial manuscript. PP, CA, FB, MPC, RC, SM, BM, CM, VM, AP, GS,CC, PR enrolled patients, collected the data, and revised the manuscript. MCD enrolled patients, collected data and critically revised the manuscript. CP conceptualized and designed the study, enrolled patients, collected data and drafted the initial manuscript. MCD and CP equally contributed to the paper. All the authors approved the final version of the manuscript.

\section{Acknowledgments}

We are grateful to the patients and their relatives who agreed to participate to this study.

\section{Author details}

'Department of Translational Medicine, "Federico II" University, Naples, Italy. ${ }^{2}$ Department of Pediatrics, (DPUO), University of Rome Tor Vergata, Rome, Italy. ${ }^{3}$ Department of Pediatrics, Anna Meyer Children's University Hospital, Florence, Italy. ${ }^{4}$ San Raffaele Telethon Institute for Gene Therapy (HSR-TIGET), Milan; Pediatric ImmunoHematology IRCCS San Raffaele Hospital, Milan, Italy. ${ }^{5}$ Department of Pediatrics, Giovanni XXIII Pediatric Hospital, Bari, Italy. ${ }^{6}$ Pediatric ImmunoHematology IRCCS, San Raffaele Hospital, Milan, Italy. ${ }^{7}$ Department of Internal and Experimental Medicine, University of Pisa, Pisa, Italy. ${ }^{8}$ Department of Pediatrics, University of Turin, Turin, Italy. ${ }^{9}$ Department of Biomedicine and Evolutive Aging, University of Bari, Bari, Italy. ${ }^{10} \mathrm{~A}$. Nocivelli Institute for Molecular Medicine, Pediatric Clinic, University of Brescia, Brescia, Italy. ${ }^{11}$ Medical Genetics Unit, General Hospital G. Rummo, Benevento, Italy. ${ }^{12}$ Medical Genetics, Bambino Gesù Pediatric Hospital, IRCCS, Rome, Italy. ${ }^{13}$ Department of Translational Medical Sciences, Unit of Pediatric Immunology, "Federico II" University, via S. Pansini, 5-80131 Naples, Italy.

Received: 17 July 2013 Accepted: 27 December 2013 Published: 2 January 2014

\section{References}

1. Devriendt K, Fryns JP, Mortier G, van Thienen MN, Keymolen K: The annual incidence of DiGeorge/velocardiofacial syndrome. J Med Genet 1998, 35:789-790.

2. Tezenas Du Montcel S, Mendizabai H, Ayme S, Levy A, Philip N: Prevalence of 22q11 microdeletion. J Med Genet 1996, 33:719.

3. Pignata C, Fiore M, Guzzetta V, Castaldo A, Sebastio G, Porta F, Guarino A: Congenital alopecia and nail dystrophy associated with severe functional T-cell immunodeficiency in two sibs. Am J Med Genet 1996, 65:167-170.

4. Pignata C, Gaetaniello L, Masci AM, Frank J, Christiano A, Matrecano E, Racioppi L: Human equivalent of the mouse nude/SCID phenotype: Long-term evaluation of immunological reconstitution after bone marrow transplantation. Blood 2001, 97:880-885.

5. Adriani M, Martinez-Mir A, Fusco F, Busiello R, Frank J, Telese S, Matrecano E, Ursini MV, Christiano AM, Pignata C: Ancestral founder mutation of the nude (FOXN1) gene in congenital severe combined immunodeficiency associated with alopecia in southern Italy population. Ann Hum Genet 2004, 68:265-268.

6. McDonald-McGinn DM, Sullivan KE: Chromosome 22q11.2 deletion syndrome (DiGeorge syndrome/velocardiofacial syndrome). Medicine (Baltimore) 2011, 90:1-18.

7. McDonald-McGinn DM, Kirschner R, Goldmuntz E, Sullivan K, Eicher P, Gerdes M, Moss E, Solot C, Wang P, Jacobs I, Handler S, Knightly C, Heher K, Wilson M, Ming JE, Grace K, Driscoll D, Pasquariello P, Randall P, Larossa D, Emanuel BS, Zackai EH: The Philadelphia story: the 22q11.2 deletion: report on 250 patients. Genet Couns 1999, 10:11-24

8. Ryan AK, Goodship JA, Wilson DI, Philip N, Levy A, Seidel H, Schuffenhauer S, Oechsler H, Belohradsky B, Prieur M, Aurias A, Raymond FL, Clayton-Smith J, Hatchwell E, McKeown C, Beemer FA, Dallapiccola B, Novelli G, Hurst JA, Ignatius J, Green AJ, Brueton L, Brondum-Nielsen K, Scambler PJ: Spectrum of clinical features associated with interstitial chromosome $22 q 11$ deletions: a European collaborative study. J Med Genet 1997, 34:798-804.

9. Digilio MC, Angioni A, De Santis M, Lombardo A, Giannotti A, Dallapiccola B, Marino B: Spectrum of clinical variability in familial deletion 22q11.2: from full manifestation to extremely mild clinical anomalies. Clin Genet 2003, 63:308-313.

10. McDonald-McGinn DM, Tonnesen MK, Laufer-Cahana A, Finucane B, Driscoll DA, Emanuel BS, Zackai EH: Phenotype of the 22q11.2 deletion in individuals identified through an affected relative: cast a wide FISHing net! Genet Med 2001, 3:23-29.

11. Defranco S, Bonissoni S, Cerutti F, Bona G, Bottarel F, Cadario F, Brusco A, Loffredo G, Rabbone I, Corrias A, Pignata C, Ramenghi U, Dianzani U: Defective function of Fas in patients with type 1 diabetes associated with other autoimmune diseases. Diabetes 2001, 50:483-488.

12. Bassett AS, Chow EW, Husted J, Weksberg R, Caluseriu O, Webb GD, Gatzoulis MA: Clinical features of 78 adults with 22q11 deletion syndrome. Am J Med Genet 2005, 38:307-313.

13. Cohen E, Chow EW, Weksberg R, Bassett AS: Phenotype of adults with the 22q11 deletion syndrome: a review. Am J Med Genet 1999, 86:359-365.

14. Motzkin B, Marion R, Goldberg R, Shprintzen R, Saenger P: Variable phenotypes in velocardiofacial syndrome with chromosomal deletion. J Pediatr 1993, 123:406-410.

15. Ravnan JB, Chen E, Golabi M, Lebo RV: Chromosome 22q11.2 microdeletions in velocardiofacial syndrome patients with widely variable manifestations. Am J Med Genet 1996, 66:250-256.

16. Goodship J, Cross I, Scambler P, Burn J: Monozygotic twins with chromosome 22q11 deletion and discordant phenotype. J Med Genet 1995, 32:746-748.

17. Halder A, Jain M, Chaudhary I, Varma B: Chromosome 22q11.2 microdeletion in monozygotic twins with discordant phenotype and deletion size. Mol Cytogenet 2012, 5:13.

18. Edelmann L, Pandita RK, Morrow BE: Low-copy repeats mediate the common 3-Mb deletion in patients with velo-cardio-facial syndrome. Am J Hum Genet 1999, 64:1076-1086.

19. Emanuel BS: Molecular mechanisms and diagnosis of chromosome 22q11.2 rearrangements. Dev Disabil Res Rev 2008, 14:11-18.

20. Shaikh TH, Kurahashi H, Saitta SC, Mizrahy O'Hare A, Hu P, Roe BA, Driscoll DA, McDonald-McGinn DM, Zackai EH, Budarf ML, Emanuel BS: Chromosome 22-specific low copy repeats and the 22q11.2 deletion syndrome: genomic organization and deletion endpoint analysis. Hum Mol Genet 2000, 9:489-501.

21. Carlson C, Sirotkin H, Pandita R, Goldberg R, McKie J, Wadey R, Patanjali SR, Weissman SM, Anyane-Yeboa K, Warburton D, Scambler P, Shprintzen R, Kucherlapati R, Morrow BE: Molecular definition of 22q11 deletions in 151 velo-cardio-facial syndrome patients. Am J Hum Genet 1997, 61:620-629.

22. Baldini A: DiGeorge syndrome: the use of model organisms to dissect complex genetics. Hum Mol Genet 2002, 11:2363-2369. 
23. Yagi H, Furutani Y, Hamada H, Sasaki T, Asakawa S, Minoshima S, Ichida F, Joo K, Kimura M, Imamura S, Kamatani N, Momma K, Takao A, Nakazawa M, Shimizu N, Matsuoka R: Role of TBX1 in human del22q11.2 syndrome. Lancet 2003, 362:1366-1373.

24. Digilio MC, Marino B, Giannotti A, Dallapiccola B: Familial deletions of chromosome 22q11. Am J Med Genet 1997, 73:95-96.

25. Leana-Cox J, Pangkanon S, Eanet KR, Curtin MS, Wulfsberg EA: Familial DiGeorge/velocardiofacial syndrome with deletions of chromosome area 22q11.2: report of five families with a review of the literature. Am J Med Genet 1996, 65:309-316.

26. Thompson PW, Davies SJ: Frequency of inherited deletions of 22q11. J Med Genet 1998, 35:789.

27. Costain G, Chow EW, Silversides CK, Bassett AS: Sex differences in reproductive fitness contribute to preferential maternal transmission of 22q11.2 deletions. J Med Genet 2011, 48:819-824.

28. Lindsay EA: Chromosomal microdeletions: dissecting del22q11 syndrome. Nat Rev Genet 2001, 2:858-868.

29. Yamagishi C, Hierck BP, Gittenberger-De Groot AC, Yamagishi H, Srivastava D: Functional attenuation of UFD1I, a 22q11.2 deletion syndrome candidate gene, leads to cardiac outflow septation defects in chicken embryos. Pediatr Res 2003, 53:546-553.

30. Breckpot J, Thienpont B, Bauters M, Tranchevent LC, Gewillig M, Allegaert K, Vermeesch JR, Moreau Y, Devriendt K: Congenital heart defects in a novel recurrent 22q11.2 deletion harboring the genes CRKL and MAPK1. Am J Med Genet 2012, 158A:574-580.

31. Rope AF, Cragun DL, Saal HM, Hopkin RJ: DiGeorge anomaly in the absence of chromosome 22q11.2 deletion. J Pediatr 2009, 155:560-565.

32. Wilson TA, Blethen SL, Vallone A, Alenick DS, Nolan P, Katz A, Amorillo TP, Goldmuntz E, Emanuel BS, Driscoll DA: DiGeorge anomaly with renal agenesis in infants of mothers with diabetes. Am J Med Genet 1993, 47:1078-1082

33. de la Chapelle A, Herva R, Koivisto M, Aula P: A deletion in chromosome 22 can cause DiGeorge syndrome. Hum Genet 1981, 57:253-256.

34. Cuturilo G, Menten B, Krstic A, Drakulic D, Jovanovic I, Parezanovic V, Stevanovic M: 4q34.1-q35.2 deletion in a boy with phenotype resembling 22q11.2 deletion syndrome. Eur J Pediatr 2011, 170:1465-1470.

35. Greenberg F, Courtney KB, Wessels RA, Huhta J, Carpenter RJ, Rich DC, Ledbetter DH: Prenatal diagnosis of deletion 17p13 associated with DiGeorge anomaly. Am J Med Genet 1988, 31:1-4.

36. Pignata C, D'Agostino A, Finelli P, Fiore M, Scotese I, Cosentini E, Cuomo C Venuta S: Progressive deficiencies in blood T cells associated with a 10p12-13 interstitial deletion. Clin Immunol Immunopathol 1996, 80:9-15.

37. Dror Y, Grunebaum E, Hitzler J, Narendran A, Ye C, Tellier R, Edwards V, Freedman $\mathrm{MH}$, Roifman CM: Purine nucleoside phosphorylase deficiency associated with a dysplastic marrow morphology. Pediatr Res 2004, 55:472-477.

38. Baldini A: The $22 q 11.2$ deletion syndrome: a gene dosage perspective. Sci World J 2006, 6:1881-1887.

39. Guo T, McDonald-McGinn DM, Blonska A, Shanske A, Bassett AS, Chow E, Bowser M, Sheridan M, Beemer F, Devriendt K, Swillen A, Breckpot J, Digilio MC, Marino B, Dallapiccola B, Carpenter C, Zheng X, Johnson J, Chung J, Higgins AM, Philip N, Simon TJ, Coleman K, Heine-Suner D, Rosell J, Kates W, Devoto M, Goldmuntz E, Zackai E, Wang T, Shprintzen R, Consortium. ICq, et al: Genotype and cardiovascular phenotype correlations with TBX1 in 1,022 velo-cardio-facial/DiGeorge/22q11.2 deletion syndrome patients. Hum Genet 2011, 32:1278-1289.

40. Herman SB, Guo T, McGinn DM, Blonska A, Shanske AL, Bassett AS, Chow EW, Bowser M, Sheridan M, Beemer F, Devriendt K, Swillen A, Breckpot J, Digilio MC, Marino B, Dallapiccola B, Carpenter C, Zheng X, Johnson J, Chung J, Higgins M, Philip N, Simon T, Coleman K, Heine-Suner D, Rosell J, Kates W, Devoto M, Zackai E, Wang T, et al: Overt cleft palate phenotype and TBX1 genotype correlations in velo-cardio-facial/DiGeorge/22q11.2 deletion syndrome patients. Am J Med Genet 2012, 158A:2781-2787.

41. Digilio MC, Marino B, Capolino R, Angioni A, Sarkozy A, Roberti MC, Conti E, de Zorzi A, Dallapiccola B: Familial recurrence of nonsyndromic congenital heart defects in first degree relatives of patients with deletion 22q11.2. Am J Med Genet 2005, 134A:158-164.

42. Swaby JA, Silversides CK, Bekeschus SC, Piran S, Oechslin EN, Chow EW, Bassett AS: Complex congenital heart disease in unaffected relatives of adults with 22q11.2 deletion syndrome. Am J Cardiol 2011, 107:466-471.
43. Calderón JF, Puga AR, Guzmán ML, Astete CP, Arriaza M, Aracena M, Aravena T, Sanz P, Repetto GM: VEGFA polymorphisms and cardiovascular anomalies in 22q11 microdeletion syndrome: a case-control and familybased study. Biol Res 2009, 42:461-468.

44. Goldmuntz E, Driscoll DA, Emanuel BS, McDonald-McGinn D, Mei M, Zackai E, Mitchell LE: Evaluation of potential modifiers of the cardiac phenotype in the 22q11.2 deletion syndrome. Birth Defects Res A Clin Mol Teratol 2009, 85:125-129.

45. Beckmann JS, Estivill X, Antonarakis SE: Copy number variants and genetic traits: closer to the resolution of phenotypic to genotypic variability. Nat Rev Genet 2007, 8:639-646.

46. Carelle-Calmels N, Saugier-Veber P, Girard-Lemaire F, Rudolf G, Doray B, Guérin E, Kuhn $P$, Arrivé M, Gilch C, Schmitt E, Fehrenbach S, Schnebelen A, Frébourg T, Flori E: Genetic compensation in a human genomic disorder. N Engl J Med 2009, 360:1211-1216

47. Vallaster M, Vallaster CD, Wu SM: Epigenetic mechanisms in cardiac development and disease. Acta Biochim Biophys Sin (Shanghai) 2012, 44:92-102.

48. Voss AK, Vanyai HK, Collin C, Dixon MP, McLennan TJ, Sheikh BN, Scambler P, Thomas T: MOZ regulates the Tbx1 locus, and Moz mutation partially phenocopies DiGeorge syndrome. Dev Cell 2012, 23:652-663.

49. Cao Z, Yu R, Dun K, Burke J, Caplin N, Greenaway T: 22q11.2 deletion presenting with severe hypocalcaemia, seizure and basal ganglia calcification in an adult man. Intern Med J 2011, 41:63-66.

50. Corneli G, Di Somma C, Prodam F, Bellone S, Gasco V, Bldelli R, Rovere S, Schneider HJ, Gargantini L, Gastaldi R, Ghizzoni L, Valle D, Salerno M, Colao A, Bona G, Ghigo E, Maghnie M, Aimaretti G: Cut-off limits of the GH response to GHRH plus arginine test and IGF-I levels for the diagnosis of $\mathrm{GH}$ deficiency in late adolescents and young adults. Eur J Endocrinol 2007, 157:701-708.

51. Cerbone M, Bravaccio C, Capalbo D, Polizzi M, Wasniewska M, Cioffi D, Improda N, Valenzise M, Bruzzese D, De Luca F, Salerno M: Linear growth and intellectual outcome in children with long-term idiopathic subclinical hypothyroidism. Eur J Endocrinol 2011, 164:591-597.

52. Salerno M, Esposito V, Farina V, Radetti G, Umbaldo A, Capalbo D, Spinelli L, Muzzica S, Lombardi G, Colao A: Improvement of cardiac performance and cardiovascular risk factors in children with GH deficiency after two years of GH replacement therapy: an observational, open, prospective, case-control study. J Clin Endocrinol Metab 2006, 91:1288-1295.

53. Wasniewska M, Corrias A, Aversa T, Valenzise M, Mussa A, De Martino L, Lombardo F, De Luca F, Salerno M: Comparative evaluation of therapy with L-thyroxine versus no treatment in children with idiopathic and mild subclinical hypothyroidism. Horm Res Paediatr 2012, 77:376-381.

doi:10.1186/1471-2350-15-1

Cite this article as: Cirillo et al:: Intergenerational and intrafamilial phenotypic variability in 22q11.2 Deletion syndrome subjects. BMC Medical Genetics 2014 15:1.

\section{Submit your next manuscript to BioMed Central and take full advantage of:}

- Convenient online submission

- Thorough peer review

- No space constraints or color figure charges

- Immediate publication on acceptance

- Inclusion in PubMed, CAS, Scopus and Google Scholar

- Research which is freely available for redistribution 